\title{
Hydrogen peroxide: a Jekyll and Hyde signalling molecule
}

\author{
DR Gough ${ }^{1}$ and TG Cotter ${ }^{\star 1}$
}

Reactive oxygen species (ROS) are a group of molecules produced in the cell through metabolism of oxygen. Endogenous ROS such as hydrogen peroxide $\left(\mathrm{H}_{2} \mathrm{O}_{2}\right)$ have long been recognised as destructive molecules. The well-established roles they have in the phagosome and genomic instability has led to the characterisation of these molecules as non-specific agents of destruction. Interestingly, there is a growing body of literature suggesting a less sinister role for this Jekyll and Hyde molecule. It is now evident that at lower physiological levels, $\mathrm{H}_{2} \mathrm{O}_{2}$ can act as a classical intracellular signalling molecule regulating kinase-driven pathways. The newly discovered biological functions attributed to ROS include proliferation, migration, anoikis, survival and autophagy. Furthermore, recent advances in detection and quantification of ROS-family members have revealed that the diverse functions of ROS can be determined by the subcellular source, location and duration of these molecules within the cell. In light of this confounding paradox, we will examine the factors and circumstances that determine whether $\mathrm{H}_{2} \mathrm{O}_{2}$ acts in a pro-survival or deleterious manner.

Cell Death and Disease (2011) 2, e213; doi:10.1038/cddis.2011.96; published online 6 October 2011

Subject Category: Experimental Medicine

Reactive oxygen species (ROS) are a family of molecules that include highly reactive free oxygen radicals (e.g., superoxide anion $\left[\mathrm{O}_{2} \cdot{ }^{-}\right]$and the hydroxyl radical $\left.\left[\mathrm{OH}^{-}\right]\right)$and the stable 'diffusable' non-radical oxidants (e.g., hydrogen peroxide $\left.\left[\mathrm{H}_{2} \mathrm{O}_{2}\right]\right) . \mathrm{H}_{2} \mathrm{O}_{2}$ and superoxide have been the main investigative foci of ROS biology in recent years, and given the fact that superoxide is rapidly converted to $\mathrm{H}_{2} \mathrm{O}_{2}$ in the cell, we will concentrate on $\mathrm{H}_{2} \mathrm{O}_{2}$ as the principal ROS member. $\mathrm{H}_{2} \mathrm{O}_{2}$ was first isolated by Thénard in 1818 and it was quickly recognised that high concentrations of $\mathrm{H}_{2} \mathrm{O}_{2}$ result in cell injury by damaging key cellular molecules such as DNA and lipids. ${ }^{1}$ Later, elevated levels of ROS became synonymous with genomic instability prompting cell death or carcinogenesis. ${ }^{2}$

Commoner et al. ${ }^{3}$ first described biological ROS production in 1954. Nearly a decade later, landmark discoveries occurred, identifying two major sources of such ROS, mitochondrial superoxide generation and the phagocytic respiratory burst. The first record of mitochondrial superoxide generation was reported by Boveris et al. ${ }^{4}$ During oxidative phosphorylation and transfer of energy along the electron transport chain, $1-5 \%$ of electrons escape from complexes
I and III, forming superoxide prematurely in the presence of oxygen. ${ }^{5}$ This process of superoxide generation, termed electron leak, has been implicated in the pathophysiology of numerous diseases. ${ }^{6}$ Babior, in the 1960 s, was among the first to suggest a role for ROS in innate immunity. He hypothesised that the elevated leukocyte oxygen consumption and the concurrent increase in cellular $\mathrm{O}_{2}$. ${ }^{-}$accompanying bacterial phagocytosis was vital to the bactericidal activity of granulocytes. ${ }^{7}$ The rapid increase in the redox status of neutrophils and macrophages while engulfing pathogens became known as the 'respiratory burst'. The enzyme responsible was named gp91phox, now known as NADPH oxidase-2 (Nox2). ${ }^{8}$

In the 1970s, a small collection of studies reported that exogenously added $\mathrm{H}_{2} \mathrm{O}_{2}$ could mimic the signalling activity of insulin. ${ }^{9}$ This revelation remained within small free radical research circles until publications in the 1980s reported that exogenous $\mathrm{H}_{2} \mathrm{O}_{2}$ could also stimulate cell proliferation at lower concentrations. ${ }^{10}$ Subsequent research into the ROSgenerating Nox enzymes revealed the true physiological roles of endogenous $\mathrm{H}_{2} \mathrm{O}_{2} .{ }^{11}$ Interest in the Nox family intensified in

\footnotetext{
${ }^{1}$ Tumour Biology Laboratory, Biochemistry Department, Bioscience Research Institute, University College Cork, Cork, Ireland

${ }^{*}$ Corresponding author: TG Cotter, Tumour Biology Laboratory, Biochemistry Department, Bioscience Research Institute, University College Cork, Cork 021, Ireland. Tel: + 35321490 1321; Fax: + 35321490 1382; E-mail: t.cotter@ucc.ie

Keywords: NADPH oxidase; reactive oxygen species; redox signalling

Abbreviations: ROS, reactive oxygen species; $\mathrm{H}_{2} \mathrm{O}_{2}$, hydrogen peroxide; $\mathrm{O}_{2} \cdot{ }^{-}$, superoxide; $\mathrm{OH}^{-}$, hydroxyl radical; Nox, $\mathrm{NADPH}$ oxidase; FAD, flavin adenine dinucleotide; $\mathrm{DCFH}_{2} \mathrm{DA}$, dichlorodihyrofluorescein diacetate; DHE, dihydroethidium; DHR, dihydrorhodamine; GFP, green fluorescent protein; roGFP, reductionoxidation-sensitive green fluorescent protein; HyPER, hydrogen peroxide sensor; Prx1, peroxiredoxin-1; NO, nitric oxide; NOS, nitric oxide synthase; RNS, reactive nitrogen species; $\mathrm{ONOO}^{-}$, peroxynitrite; $\mathrm{NO}_{2}$, nitrogen dioxide; PTK, protein tyrosine kinase; PTP, protein tyrosine phosphatase; DSP, dual-specificity phosphatase; ERK, extracellular signal-regulated kinase; EPO, erythropoietin; PTEN, phosphatase and tensin homologue; PIP, phosphatidylinositol triphosphate; TNF, tumour necrosis factor; TGF, transforming growth factor; HIF, hypoxia-inducible factor; AP-1, activator protein-1; PDGF, platelet-derived growth factor; IFN, interferon; LPS, lipopolysaccharide; STAT, signal transducer and activator of transcription; PKC, protein kinase-C; VSMC, vascular smooth muscle cell; PMA, phorbol-12-myristate-13acetate; EGFR, epidermal growth factor receptor; WRN, Werner protein gene; BLT2, leukotriene-B4 receptor-2; ECM, extracellular matrix; ANGPTL4, angiopoietinrelated protein-4

Received 30.6.11; revised 31.8.11; accepted 31.8.11; Edited by A Finazzi-Agró
} 
the 90 s and 00s. Gene profiling of gp91phox; identification of seven Nox isoforms (Nox1-5 and Duox1 and 2) and subunits (p67phox, p47phox, p40phox, and Rac1/2); and prolific expression of these enzymes in non-phagocytic cell types became clear through the work of David Lambeth ${ }^{12}$ and others. It was demonstrated that Nox enzymes have a fundamental role in numerous physiological processes, including survival signalling.

Pivotal to this expanding field of research was elucidating the precise mechanism through which $\mathrm{H}_{2} \mathrm{O}_{2}$ and other ROS could modulate signalling pathways. The widely accepted hypothesis proposed by the Tonks group describes reversible inhibition of phosphatases that negatively regulate signalling cascades through oxidation of redox-sensitive cysteine residues. ${ }^{13}$ We now know that ROS have opposing roles in the cell under specific conditions. This review will examine factors such as source and site of $\mathrm{H}_{2} \mathrm{O}_{2}$ formation to further discuss this conflicting role of cellular ROS.

\section{Cellular ROS Generation}

Nox enzymes, activated by various growth factors and cytokines, generate $\mathrm{H}_{2} \mathrm{O}_{2}$ or $\mathrm{O}_{2} \cdot{ }^{-}$for signalling processes such as proliferation, migration and survival. ${ }^{14}$ Several other sources of endogenous ROS exist such as mitochondria, xanthine oxidase, lipoxygenase and myeloperoxidase. Notably, they fail to show the diverse physiological functions attributed to the Nox family, and hence, will not be discussed further.

The original hypothesis of Nox-mediated ROS generation is based on the gp91phox/Nox2 prototype characterising Nox proteins as integral membrane proteins (Figure 1). Six transmembrane domains form a channel to allow successive transfer of electrons. Electrons are transferred from NADPH (converting it to $\mathrm{NADP}^{-}$) to flavin adenine dinucleotide (FAD) to haeme and finally to oxygen to form superoxide. ${ }^{12}$ Neutrophil stimulation leads to the assembly of an active
Nox2 complex at the plasma membrane. This complex comprises a catalytic subunit, the integral membrane protein gp91phox and a p22phox subunit. Activation of this catalytic core relies on the recruitment of several cytosolic protein subunits. ${ }^{15}$ This complex then releases $\mathrm{O}_{2} \cdot{ }^{-}$at micromolar concentrations into the phagosome, killing the pathogen, a process known as the respiratory burst. ${ }^{16}$ By contrast, little is known about the assembly/activation of the other Nox-family members. Cytokines and growth factors induce ROS production through activation of locally recruited Noxs in nonphagocytic cell types. ${ }^{14}$ Nox1, 2, 3 and 5 produce $\mathrm{O}_{2} \cdot{ }^{-}$, whereas Duox1 and 2, and more recently Nox4, are known to produce $\mathrm{H}_{2} \mathrm{O}_{2}$ directly because to a peroxidase-like domain at their N-terminus. ${ }^{17,18}$ The consequence of differential production of ROS members by Nox enzymes has yet to be established.

Accurate quantification and localisation of $\mathrm{H}_{2} \mathrm{O}_{2}$ have been the rate-limiting factors in ROS cell signalling research. This stumbling block is further compounded by recent evidence suggesting that $\mathrm{H}_{2} \mathrm{O}_{2}$ is not as freely diffusible as once thought. Miller et al. ${ }^{19}$ demonstrated that aquaporin-3 regulated the transmembrane movement of Nox-derived $\mathrm{H}_{2} \mathrm{O}_{2}$. The most prevalent method of imaging biological ROS is through use of fluorescent redox-sensitive dyes such as $2^{\prime}, 7^{\prime}$-dichlorofluorescein diacetate or similar (dihydroethidium, dihydrorhodamine, MitoSox Red and Amplex Red) (Figure 2). Widely acknowledged reservations exist regarding specificity, cell/tissue uptake and subcellular diffusion dynamics of fluorescent dyes that demand cautious interpretation. ${ }^{20}$ Fluorescent probes such as green fluorescent protein (GFP) and variants (e.g., reduction-oxidation-sensitive GFP (roGFP) and hydrogen peroxide sensor (HyPER)) incorporate redox-sensitive cysteines, becoming fluorescent in the presence of particular ROS. ${ }^{21}$ The advantages of fluorescent probes include greater sensitivity and specificity, signal reversibility and easy modification with targeting sequences to allow subcellular expression, for example,

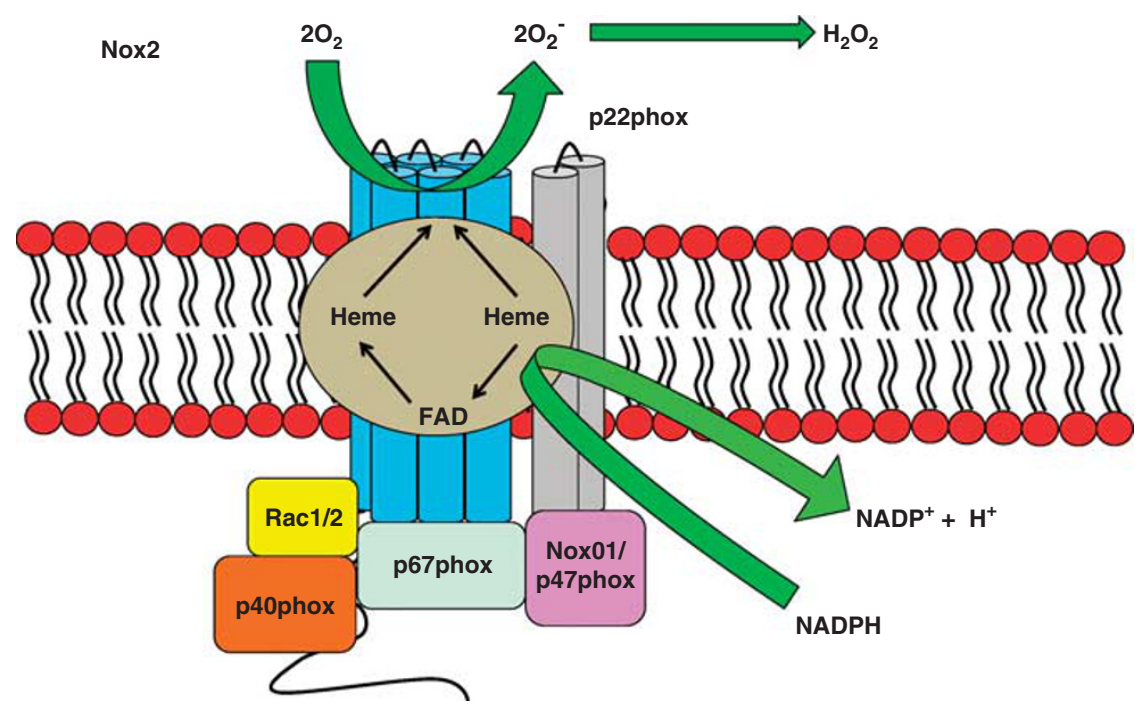

Figure 1 Nox2 structure. Exposure to pathogenic organism triggers Nox2 complex assembly in the neutrophil by recruiting various subunits to the plasma membrane. The activated Nox complex then releases superoxide in micromolar concentrations into the phagosome, thus killing the pathogen 
endoplasmic reticulum. ${ }^{22}$ Further developments include generation of transgenic animals expressing these redoxsensitive proteins, thus creating invaluable in vivo models, for example, zebrafish. ${ }^{23}$ Several cell-free assays have been used to measure $\mathrm{O}_{2} \cdot{ }^{-}$and $\mathrm{H}_{2} \mathrm{O}_{2}$ production as a reflection of Nox activity, yet these methods shed little light on $\mathrm{H}_{2} \mathrm{O}_{2}$ as a second messenger molecule in subcellular domains. ${ }^{24}$

We now understand that non-phagocytic Nox enzymes are no longer confined to the plasma membrane. They have been identified in numerous subcellular compartments such as the endoplasmic reticulum, nucleus and mitochondria. ${ }^{22,25,26}$ The seven Nox isoforms show a complex heterogeneity in which one or more isoforms may be located in several subcellular compartments within a single cell type. ${ }^{27}$ This expression profile is echoed by the varied subcellular expression levels of both antioxidant enzymes and redox-sensitive protein targets. $^{28}$ Indeed expression of Nox enzymes in specific subcellular locations can dictate participation in distinct

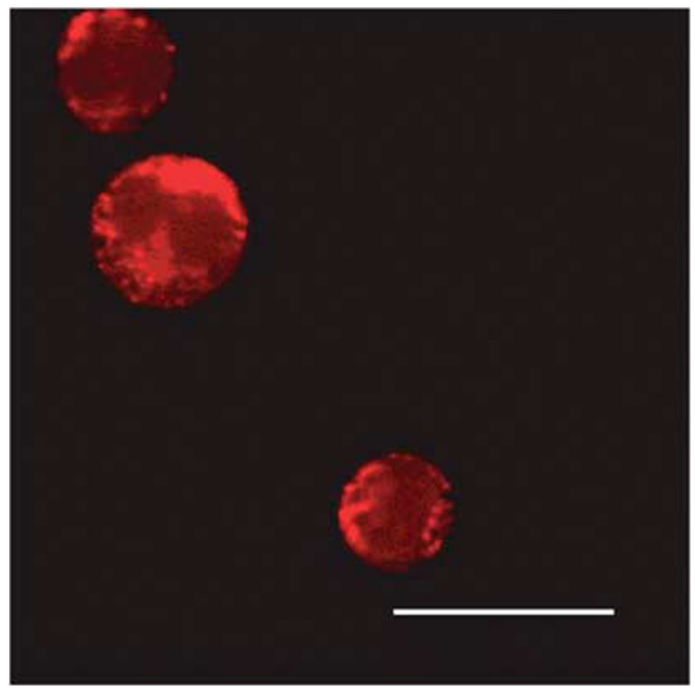

Figure 2 Subcellular localisation of Nox-generated $\mathrm{H}_{2} \mathrm{O}_{2}$. Multi-photon microscopy images of Nox-generated ROS in MV411 acute myeloid leukaemia cells (courtesy of Dr Lavinia Bhatt). The ROS-sensitive dye, Peroxy Orange-1 (P01), stains red in the presence of ROS. The fluorescence observed shows a staining pattern consistent with the endoplasmic reticulum signalling pathways. Ushio-Fukai ${ }^{29}$ published a thorough review on the compartmentalisation of Noxs affecting immune signalling pathways. Several papers describing compartmentalised $\mathrm{H}_{2} \mathrm{O}_{2}$ survival signalling have emerged recently. ${ }^{30-32}$

A complex array of enzymatic (i.e., superoxide dismutase, catalase, thioredoxin and peroxiredoxin (Prx)) and nonenzymatic (i.e., glutathione; flavonoids; and vitamins $A, C$ and $E$ ) antioxidant systems protect cells against $R O S$ damage (Table 1). Effective antioxidant activity is necessary to buffer fluctuations in the cellular redox status and avoid irreversible oxidation of integral cellular macromolecules such as proteins, lipids and DNA. Recent data have shown that certain antioxidant members are precisely regulated by Nox-driven signalling to channel $\mathrm{H}_{2} \mathrm{O}_{2}$ to colocalised target proteins. Toledano et al. ${ }^{33}$ examine reversible inactivation through phosphorylation of Prx1 colocalised to Nox, c-Src and receptor tyrosine kinases. In consequence to growth factor and cytokine stimulation, kinase-driven pathways are thought to both activate Nox activity and moreover, phosphorylate and thus inactivate local Prx1. This process ensures direct, efficient $\mathrm{H}_{2} \mathrm{O}_{2}$ delivery to the target protein.

The intimate relationship that exists between nitric oxide (NO -), another second messenger molecule, and the ROS family warrants mention. NO synthases (NOSs) metabolise arginine to citrulline and generate freely diffusible NO., a small diatomic molecule with one unpaired electron. At lower concentrations, $\mathrm{NO}$ - reacts with certain target proteins mainly through post-translational $S$-nitrosylation, thus regulating cell survival, smooth muscle tone and immune signalling. ${ }^{34}$ Higher concentrations of NO. often trigger 'indirect reactions' requiring an intermediary reaction with oxygen or $\mathrm{O}_{2}^{-}$to produce reactive nitrogen species (RNS). This well-recognised crosstalk with ROS members is known to generate a spectrum of harmful oxidants comparable to excessive ROS, including peroxynitrite $\left(\mathrm{ONOO}^{-}\right)$and nitrogen dioxide $\left(\mathrm{NO}_{2}\right)$. This strangely familiar dichotomy, mirroring ROS biology, is governed by similar parameters, including subcellular location and concentration. The double-edged sword nature of NO reactions is exemplified in the setting of apoptosis. Overproduction of RNS (nitrosative stress), as with oxidative stress, can potentially trigger cell death processes such as DNA fragmentation and lipid oxidation. ${ }^{35}$ However, RNS can also have a protective role involving nitrosation of caspases and PARP, leading to inhibition of apoptosis. ${ }^{36}$

Table 1 Enzymatic antioxidants

\begin{tabular}{llll}
\hline Enzymatic antioxidant & Cellular location & Substrate & Reaction \\
\hline Superoxide dismutase (Mn/Cu/ZnSOD) & $\begin{array}{l}\text { Mitochondrial matrix (MnSOD) } \\
\text { Cytosol (Cu/ZnSOD) }\end{array}$ & Superoxide $\left(\mathrm{O}_{2} \cdot \cdot^{-}\right)$ & $\mathrm{O}_{2} \cdot{ }^{-} \rightarrow \mathrm{H}_{2} \mathrm{O}_{2}$ \\
Catalase & $\begin{array}{l}\text { Peroxisomes } \\
\text { Cytosol }\end{array}$ & Hydrogen peroxide $\left(\mathrm{H}_{2} \mathrm{O}_{2}\right)$ & $2 \mathrm{H}_{2} \mathrm{O}_{2} \rightarrow \mathrm{O}_{2}+\mathrm{H}_{2} \mathrm{O}$ \\
Glutathione peroxidase (GPX) & Cytosol & Hydrogen peroxide $\left(\mathrm{H}_{2} \mathrm{O}_{2}\right)$ & $\mathrm{H}_{2} \mathrm{O}_{2}+\mathrm{GSH}_{\rightarrow} \rightarrow \mathrm{GSSG}_{+}+\mathrm{H}_{2} \mathrm{O}$ \\
Peroxiredoxin I $\rightarrow$ VI (Prx) & Cytosol & Hydrogen peroxide $\left(\mathrm{H}_{2} \mathrm{O}_{2}\right)$ & $\mathrm{H}_{2} \mathrm{O}_{2}+\mathrm{TrXS}_{2} \rightarrow \mathrm{Trx}(\mathrm{SH})_{2}+\mathrm{H}_{2} \mathrm{O}$
\end{tabular}

Superoxide dismutases (SODs) catalyse the breakdown of superoxide into oxygen and $\mathrm{H}_{2} \mathrm{O}_{2}$. These enzymes, located in the cytosol and mitochondria, require a metal ion cofactor, copper $(\mathrm{Cu})$, zinc $(\mathrm{Zn})$ or manganese $(\mathrm{Mn})$. Catalase is localised to the peroxisome, where it converts $\mathrm{H}_{2} \mathrm{O}_{2}$ to water and oxygen. $\mathrm{Glutathione}$ peroxidases are a large family of enzymes that reduce $\mathrm{H}_{2} \mathrm{O}_{2}$ to water. They are found both in the cytoplasm and extracellularly in almost every human tissue. Prxs catalyse the reduction of $\mathrm{H}_{2} \mathrm{O}_{2}$, organic hydroperoxides as well as peroxynitrite $\left(\mathrm{ONOO}^{-}\right)$. Please note that several non-enzymatic antioxidants exist, including thioredoxin; vitamin A, C and E; and melatonin. The varied expression profiles, subcellular locations and substrates of the above mentioned antioxidant systems reflect the complex nature of ROS biology. It is clear that they are vital to escape oxidative damage and ensure cell survival 


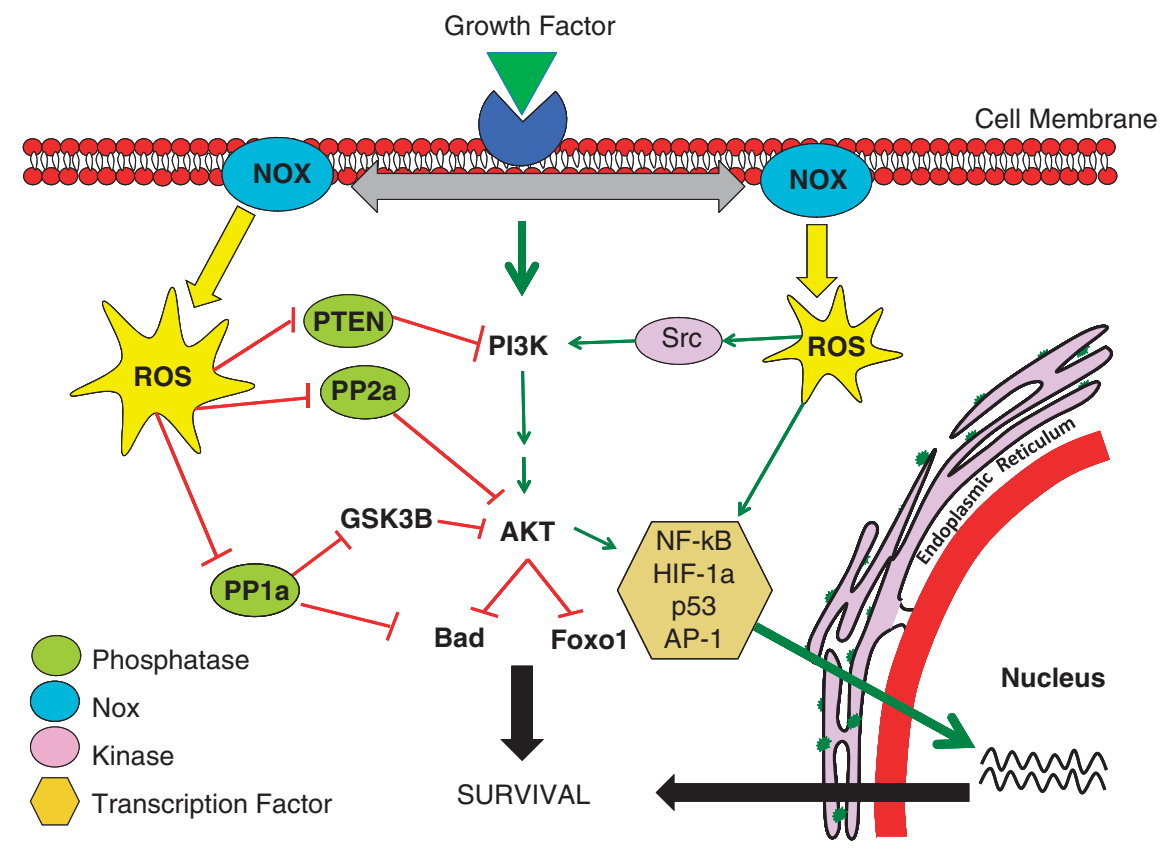

Figure 3 Nox regulation of the PI3K/AKT pathway. Activation of Nox activity occurs upon growth factor stimulation. This happens through recruitment of various protein subunits or by induction of Nox isoform expression. Nox-derived $\mathrm{H}_{2} \mathrm{O}_{2}$ then regulates kinase-driven survival signalling, for example, the PI3K/AKT pathway, by three major mechanisms. The cysteine residues located at the active sites of specific phosphatases are susceptible to reversible oxidation. This oxidation results in the inhibition of these phosphatases that negatively regulate survival signalling, thus propagating a pro-survival effect. Nox-generated ROS can also stimulate many pro-survival kinases (Src) and transcription factors (NF-kB), resulting in enhanced survival signalling

\section{Redox Protein Targets}

Understanding the mechanism through which $\mathrm{H}_{2} \mathrm{O}_{2}$ modulates signalling pathways is paramount to unearthing the signalling role of Noxs. In keeping with Nox activity, finely controlled, modest fluctuations of the cellular redox status have been shown to be capable of reversible modulation of signalling cascades. Three principal mechanisms of survival pathway activation have been proposed: (a) inhibition of phosphatases, (b) activation of tyrosine kinases and (c) transcription factor activation (Figure 3).

A large body of evidence identifies cysteine residues as the most likely targets of Nox-generated ROS. Reversible oxidation of cysteine residues occurs when sulphenic acid intermediates (Cys-SOH) are formed. Reversal of this reaction is mediated by incubation with thiol compounds. Interestingly, this process of protein reduction is thought to be equally significant as Nox enzymes in the redox regulation of signalling pathways. ${ }^{37}$ Importantly, exposure of the highly conserved cysteine residue to excessive ROS leads to irreversible oxidation of the cysteine residue to sulphinic and sulphonic acid, a process that often accompanies cell death/ injury processes. ${ }^{38,39}$ Several signalling pathways are driven by protein tyrosine kinases (PTKs) through phosphorylation. ${ }^{40}$ By contrast, phosphatases dephosphorylate signalling proteins, resulting in their inactivation. Phosphatases, a structurally diverse family of receptor-like non-transmembrane enzymes, target specific substrates in vivo and are critical regulators of signalling pathways. The phosphatase super-family includes protein tyrosine phosphatases (PTPs), dual-specificity phosphatases (DSPs) and serine/threonine phosphatases. ${ }^{14}$

PTPs, including PTP-1B, SHP1 and SHP2, represent the most well-described in vivo targets of Nox-mediated $\mathrm{H}_{2} \mathrm{O}_{2}$ signalling. The PTP signature motif, $\mathrm{HC}(\mathrm{X}) 5 \mathrm{R}(\mathrm{S} / \mathrm{T})$, creates a unique environment for the catalytic cysteine residue. The presence of a conserved arginine residue confers an unusually low $\mathrm{p} K_{\mathrm{a}}$, hence rendering the cysteine residue highly susceptible to oxidation. ${ }^{13}$ Oxidation of the cysteine residue results in inhibition of activity because the modified cysteine can no longer function as a phosphate acceptor. Colocalisation of Nox4 and PTP-1B at the endoplasmic reticulum results in enhanced extracellular signal-regulated (ERK) signalling and proliferation upon reversible cysteine oxidation. ${ }^{22}$ Nox2 activity has been shown to inactivate SHP2 phosphatases thus enhancing erythropoietin (EPO)-induced STAT5 (signal transducer and activator of transcription-5) signalling. ${ }^{41}$ Oxidative inhibition of DSPs such as phosphatase and tensin homologue (PTEN) and cdc25 results in the formation of a disulphide bond between oxidised cysteines inactivating phosphatase activity and furthermore preventing irreversible oxidation. ${ }^{42}$ Oxidative inhibition, for example by Nox1, prevents PTEN-mediated dephosphorylation of lipid phosphatidylinositol triphosphate-3 (PIP3) to PIP2, allowing recruitment of $\mathrm{PH}$-containing proteins to the plasma membrane, thus augmenting PI3K/AKT survival signalling. ${ }^{43}$ The Ser/Thr phosphatases (PP1, PP2A, PP2B and PP2C) dephosphorylate serine and threonine, which are the main phosphorylation sites in the transduction of the kinase-driven PI3K/ AKT survival pathway. We demonstrated that BCR-ABL- 
induced Nox4 expression led to attenuation of PP2A activity and consequent upregulation of PI3K/AKT signalling. ${ }^{44}$

Evidence also exists for ROS-mediated activation of PTKs such as Src. For example, upon cell attachment to the extracellular matrix (ECM) and associated generation of $\mathrm{H}_{2} \mathrm{O}_{2}$, the tyrosine kinase Src becomes oxidised at two cysteine residues and thus becomes activated. ${ }^{45}$ Moreover, antioxidant treatment of cells that express an oncogenic form of Src ( $v$-Src), or mutation of v-Src cysteine residues, reduces the potency of v-Src to transform cells. ${ }^{46}$ ROS induction of gene expression has been extensively investigated. ROSmediated expression of tumour necrosis factor- $\alpha$ (TNF $\alpha$ ), transforming growth factor- $\beta 1$ (TGF- $\beta 1$ ), angiotensin and others occurs by two distinct pathways, either downstream from signalling pathways described earlier (e.g., MAPK) or through redox-sensitive transcription factors, (e.g., NF-kB, hypoxia-inducible factor-1 $\alpha$ (HIF-1 $\alpha)$, p53 and activator protein-1 (AP-1)). ${ }^{14}$ These transcription factors contain cysteine residues in their DNA-binding domains thus rendering them susceptible to oxidative modulation. It has been shown that Src-mediated activation of HIF- $1 \alpha$ occurs through Nox-generated ROS and not by direct phosphorylation as previous thought. ${ }^{47}$

$\mathrm{H}_{2} \mathrm{O}_{2}$ can modulate enzyme activity by several differing mechanisms (Figure 3). Identification of specific protein targets of Nox-mediated ROS is vital to delineating their ever-expanding roles in cellular signalling pathways.

\section{Growth Factor-Induced ROS Generation}

Nox activity increases upon stimulation of the relevant receptors and regulates many downstream survival signalling pathways, including PI3K/AKT and MAPK. ${ }^{48}$ Signalling mechanisms coupling growth factor receptor activation to Nox activity remain largely unknown. Nox activation in nonphagocytic cell types varies considerably and continuingly drifts away from the prototypical Nox2 paradigm. ${ }^{49}$ Various triggers result in Nox-mediated $\mathrm{H}_{2} \mathrm{O}_{2}$ generation by either (a) stimulating Nox isoform activity by recruiting or inducing various Nox regulatory subunits, or (b) by triggering Nox isoform expression.

Numerous stimuli increase non-phagocytic Nox expression. Given the large amount of contrasting data, induced expression of particular Noxs appears to be both stimulus and cell type-specific. Nox1 transcription is upregulated by growth factors receptors (platelet-derived growth factor (PDGF)), ${ }^{50}$ inflammatory mediators (interferon- $\gamma($ IFN $-\gamma)$ ), pathogenic molecules (lipopolysaccharide (LPS)), vitamin D3 and hypoxia $(\mathrm{HIF}-1 \alpha)$. GATA-6 and STAT1 have both been implicated in the transcriptional regulation of Nox $1 .{ }^{51}$ Nox4 expression occurs in a plethora of cell types, including pancreatic, vascular smooth muscle (VSMC) and myeloid cell lines. ${ }^{49}$ Activators of Nox4 transcription in smooth muscle cells include urokinase, plasminogen activator, angiotensin-II, TGF- $\beta 1$ and TNF- $\alpha .{ }^{51}$ Currently, there are little data regarding Nox4-related transcription factors and promoter structures. Duox1 and Duox2 are widely and differentially expressed throughout most human tissues. Induction of Duox1 and Duox2 expression has been elicited in response to Th1 and Th2 dominant cytokines, respectively. ${ }^{52}$ Interestingly, regulation of Duox expression in animal models by pathways such as cAMP have failed to correlate with human cell lines/ tissues. ${ }^{53}$ Despite studies identifying Duox promoter regions, a void remains pinpointing relevant transcription factors. Expression of Nox3 and Nox5 has been documented in various human tissues; however, characterisation of specific promoter regions and transcription factors remains unchecked.

Upregulation of Nox activity accounts for growth factorinduced ROS production in most cases of Nox pro-survival signalling. Nox1 and Nox3 tend to follow the original Nox2 model such that a stimulus triggers the formation of the active Nox complex, coupled with various combinations of protein subunits. These activating cytoplasmic proteins include p22phox, p47phox and homologue NoxO1, p67phox and homologue NoxA1, and Rac1/2. ${ }^{12}$ Activation of these subunits appears to rely heavily on phosphorylation by specific kinases. A resultant increase in Nox activity in response to subunit phosphorylation has only been demonstrated in the case of p47phox and Rac. Phosphorylation of p47phox by specific kinases (protein kinase-C (PKC), p38 MAPK, p21-activated kinase), removes its inherent auto-inhibition, allowing p47phox to bind to the cytoplasmic tail of p22phox, activating the Nox complex. ${ }^{54}$ Rac1/2 is a small RhoGTPase and can be bound to GDP, making it inactive, or to GTP, making it active. Guanine nucleotide exchange factors (GEFs) and guanine-activating proteins (GAPs) promote and inhibit Rac $1 / 2$ binding, respectively. ${ }^{14}$ Nearly 200 different GAPs and GEFs have been identified thus reflecting the complexity of potential Nox activation mechanisms in Racdependent Nox1\&2 alone. p22phox is known to associate with Nox4; however, whether it is required for ROS generation is uncertain. A novel p22phox-interacting protein, poldip2, has recently been shown to activate Nox4 in VSMC lines. ${ }^{55}$ By contrast, some groups claim that Nox4 is constitutively active and regulated by expression alone. ${ }^{56}$ Nox5, Duox 1 and Duox2 are activated by increased calcium concentrations, owing to EF-hand $\mathrm{Ca}^{2+}$-binding domains. It has been shown that calcium binding triggers a conformational change at the $\mathrm{N}$-terminal, thus permitting transfer of electrons. ${ }^{57}$ Jagnandan et al. ${ }^{58}$ showed that phorbol-12-myristate-13-acetate (PMA)induced ROS led to the phosphorylation of Nox5, increasing sensitivity to calcium, promoting activation at lower calcium concentrations. Although recent papers describe Nox5 regulation by PKA, PKC, PIP2 and c-Abl, activation of Nox5 by factors other than calcium remains unclear. ${ }^{59}$ Similar to Nox4 activation, the necessity for Duox-p22phox binding is of uncertain consequence. ${ }^{60}$

The novel growth factor receptor-Nox relationship continues to show exquisite heterogeneity, currently masking any potential mechanism that may transcend the spectrum of stimuli and Nox isoforms described.

\section{Nox Disease Links}

The link between Nox activity and the pathogenesis of acute and chronic diseases has been well-described. ${ }^{61}$ Cancerous cells have been frequently associated with overproduction of ROS accounted for by elevated expression and activity of Nox enzymes downstream from constitutively active growth factor 
receptors. ${ }^{62}$ Nox enzymes are inherent to processes synonymous with tumour phenotypes such as enhanced survival signalling, proliferation, angiogenesis and metastasis owing to a novel oncogene-Nox relationship. ${ }^{63-65}$

Several oncogenes and constitutively active growth factor receptors are known to upregulate both Nox activity and expression, including Ras, Flt3 and BCR-ABL, by mechanisms described in the previous section. Jung et al. demonstrated the oncogenic effect of translationally controlled tumour protein (TCTP) in breast cancer cells. Augmented Nox activity/expression correlated with upregulated epidermal growth factor receptor (EGFR), PI3K/AKT, ERK activity and matrix metalloproteinase expression. ${ }^{66}$ This exemplifies not only the unique oncogene-Nox relationship, but also the many Nox-driven processes underlying tumour progression. Upregulation of Nox1 and increased Nox1 mRNA levels have been shown to correlate well with oncogenic mutations in K-Ras. ${ }^{67}$ FLT3-ITD receptors maintain Nox signalling by phosphorylating STAT5, which colocalises to Rac1, thus regulating the activity of Nox1 and Nox2. ${ }^{68}$

The setting of elevated ROS production, termed oxidative stress, has long been known to promote genomic instability, augmenting favourable growth mutations and chemoresistance. ${ }^{69}$ Nox2 activity-induced genomic instability was responsible for the tumour-promoting mechanism of the oncogenic Epstein-Barr virus (EBV) nuclear antigen (EBNA) $-1 .{ }^{70}$ The recognised internal tandem duplication mutation of the FLT3 receptor (FLT3-ITD) augmented Nox-generated ROS, leading to elevated double-stranded DNA break frequency. ${ }^{68}$ Slupianek et al. ${ }^{71}$ highlighted a bimodal mutagenic effect of BCR-ABL through induction of Nox-mediated DNA damage coupled with dysregulation of DNA-repair mechanisms by Werner protein gene (WRN) activation. Clearly, Nox-generated ROS under certain conditions can potentially promote genomic instability irrespective of their intended protein targets.

Several tumour cell types also demonstrate increased antioxidant capacity correlating well with oxidative stress, suggesting that enhanced antioxidant activity is necessary for tumour progression. H-Ras-transformed cells, known to produce high levels of ROS, also expressed elevated levels of Prx1 and thioredoxin peroxidase when compared with their benign parental cells. ${ }^{72}$ In melanoma cells, pro-survival c-Myc was shown to upregulate GSH, conferring survival benefit. ${ }^{73}$ Interestingly, this adaptive upregulation of antioxidant enzymes is also known to confer chemoresistance to cancer cells when exposed to certain chemotherapeutic drug classes, for example, taxanes. ${ }^{74}$

Given the exaggerated nature of tumour cell survival pathways, the majority of studies describing pro-survival Nox signalling involve cancer cell types. Mochizuki et al. ${ }^{75}$ showed that Nox4 activated the AKT/ASK1 pathway in pancreatic PANC1 tumour cells. Nox4 also has a role in NF- $k B$ survival signalling in melanoma cells. ${ }^{76}$ Ras is known to promote invasion and metastasis through a unique pathway in which leukotriene-B4 receptor-2 (BLT2) stimulated Nox1, activating NF- $k B$ and leading to a subsequent upregulation of matrix metalloproteinase- $9 .^{77}$

While most literature implicating Nox survival signalling appears to lack coherency, its role in protection from anoikis is well elucidated. Anoikis is the apoptotic process induced by loss of contact with the ECM observed typically in nontransformed adherent cells. Integrin activation through ECMcell contact stimulates Rac1-dependent intracellular ROS production during cell spreading. ${ }^{78}$ The proposed target of the ROS, the tyrosine kinase, Src, participates in the crosstalk between ECM contact and the propagation of survival signalling. Oxidised Src then promotes ligand-independent phosphorylation and activation of EGFR. Downstream signalling through ERK and Akt pathways results in the phosphorylation and degradation of the pro-apoptotic protein Bim, thus escaping apoptosis. ${ }^{79}$ It was recently demonstrated that angiopoietin-related protein-4 (ANGPTL4)-stimulated Nox1 activity can mimic anchorage-dependent growth conditions in tumour cells, thus aiding metastasis. ${ }^{80}$

Nox enzymes can have two distinct roles with regard to oncogene-driven tumour promotion. It is likely that genomic instability in the setting of increased Nox activity exists as an off-target effect. The subcellular localisation, and particularly, the proximity to the nucleus of the relevant Nox enzymes, may hold the answer to this bimodal pro-survival effect.

\section{Future Perspectives}

It is clear that Nox-generated $\mathrm{H}_{2} \mathrm{O}_{2}$ can have opposing roles in the cell owing to its novel second messenger status. The initiation and propagation of pro-survival signalling in response to ROS relies heavily on subcellular location of Nox enzymes as well as on stimulus and cell type. Several mechanisms exist through which ROS can potentially modulate signalling by oxidation. Importantly, several aspects of $\mathrm{ROS}$ signalling remain uncertain. The uncertainty regarding intracellular $\mathrm{H}_{2} \mathrm{O}_{2}$ diffusion dynamics demands clarification. The recent aquaporin-3 data coupled with the exquisite specificity of ROS signalling explicitly contradict the widely, and perhaps blindly, accepted 'freely diffusible' theory of $\mathrm{H}_{2} \mathrm{O}_{2}$. Furthermore, identification of specific ROS protein targets together with compartmentalisation of Nox activity will uncover the unique mechanisms by which Noxs regulate various cellular signalling pathways. Finally, enormous potential exists for therapeutic manipulation of the Nox-driven mechanisms of tumour promotion described earlier. In light of the disappointing performance of antioxidants in the clinical chemotherapeutic arena, targeted Nox isoform inhibition represents a novel anticancer strategy in the future.

\section{Conflict of Interest}

The authors declare no conflict of interest.

Acknowledgements. We are grateful to Professor CJ Chang (Department of Chemistry, University of California, Berkley, CA, USA) for the gift of the Peroxy Orange dye. This work is supported by the Irish Cancer Society, The Children's Leukaemia Research Project Ireland and Science Foundation Ireland.

\footnotetext{
1. Plaine $\mathrm{HL}$. The effect of oxygen and hydrogen peroxide on the action of a specific gene and on tumour induction in drosophila melanogaster. Genetics 1955; 40: 268-280.

2. Jeffree GM. Hydrogen peroxide and cancer. Nature 1958; 182: 892.

3. Commoner B, Townsend J, Pake GE. Free radicals in biological materials. Nature 1954; 174: 689-691.
} 
4. Boveris A, Oshino N, Chance B. The cellular production of hydrogen peroxide. Biochem 1972; 128: 617-630.

5. St-Pierre J, Buckingham JA, Roebuck SJ, Brand MD. Topology of superoxide production from different sites in the mitochondrial electron transport chain. J Biol Chem 2002; 277 44784-44790.

6. Monsalve M, Borniquel S, Valle I, Lamas S. Mitochondrial dysfunction in human pathologies. Front Biosci 2007; 12: 1131-1153.

7. Babior BM, Kipnes RS, Curnutte JT. Biological defense mechanisms. The production by leukocytes of superoxide, a potential bactericidal agent. J Clin Invest 1973; 52: 741-744.

8. Babior BM, Lambeth JD, Nauseef W. The neutrophil NADPH oxidase. Arch Biochem Biophys 2002; 397: 342-344.

9. Czech MP, Lawrence JC, Lynn W. Evidence for the involvement of sulfhydryl oxidation in the regulation of fat cell hexose transport by insulin. Proc Natl Acad Sci USA 1974; 71: 4173-4177.

10. Burdon $\mathrm{RH}$, Rice-Evans $\mathrm{C}$. Free radicals and the regulation of mammalian cell proliferation. Free Rad Res Comms 1989; 6: 345-358.

11. Lambeth JD. Nox enzymes, ROS, and chronic disease: an example of antagonistic pleiotropy. Free Radic Biol Med 2007; 43: 332-347.

12. Lambeth JD. NOX enzymes and the biology of reactive oxygen. Nat Rev Immunol 2004; 4 181-189.

13. Meng TC, Fukada T, Tonks NK. Reversible oxidation and inactivation of protein tyrosine phosphatases in vivo. Mol Cell 2002; 9: 387-399.

14. Groeger G, Quiney C, Cotter TG. Hydrogen peroxide as a cell-survival signaling molecule. Antioxid Redox Signal 2009; 11: 2655-2671.

15. Uhlinger DJ, Tyagi SR, Inge KL, Lambeth JD. The respiratory burst oxidase of human neutrophils. Guanine nucleotides and arachidonate regulate the assembly of a multicomponent complex in a semirecombinant cell-free system. J Biol Chem 1993 268: 8624-8631.

16. Babior BM. The respiratory burst oxidase. Curr Opin Hematol 1995; 2: 55-60.

17. Geiszt M, Witta J, Baffi J, Lekstrom K, Leto TL. Dual oxidases represent novel hydrogen peroxide sources supporting mucosal surface host defense. FASEB J 2003; 17: 1502-1504.

18. Takac I, Schröder K, Zhang L, Lardy B, Anilkumar N, Lambeth JD et al. The E-loop is involved in hydrogen peroxide formation by the NADPH oxidase Nox4. J Biol Chem 2011; 286: 13304-13313.

19. Miller EW, Dickinson BC, Chang CJ. Aquaporin-3 mediates hydrogen peroxide uptake to regulate downstream intracellular signaling. Proc Natl Acad Sci USA 2010; 107: 15681-15686

20. Murphy MP, Holmgren A, Larsson NG, Halliwell B, Chang CJ, Kalyanaraman B et al. Unraveling the biological roles of reactive oxygen species. Cell Metab 2011; 13: 361-366.

21. Kim JS, Huang TY, Bokoch GM. Reactive oxygen species regulate a slingshot-cofilin activation pathway. Mol Biol Cell 2009; 20: 2650-2660.

22. Chen K, Kirber MT, Xiao H, Yang Y, Keaney Jr JF. Regulation of ROS signal transduction by NADPH oxidase 4 localization. J Cell Biol 2008; 181: 1129-1139.

23. Niethammer $P$, Grabher $C$, Look AT, Mitchison TJ. A tissue-scale gradient of hydrogen peroxide mediates rapid wound detection in zebrafish. Nature 2009; 459: 996-999.

24. DeChatelet LR, McPhail LC, Mullikin D, McCall CE. An isotopic assay for NADPH oxidase activity and some characteristics of the enzyme from human polymorphonuclear leukocytes. J Clin Invest 1975; 55: 714-721.

25. Liu RM, Choi J, Wu JH, Gaston Pravia KA, Lewis KM, Brand JD et al. Oxidative modification of nuclear mitogen-activated protein kinase phosphatase 1 is involved in transforming growth factor beta1-induced expression of plasminogen activator inhibitor 1 in fibroblasts. J Biol Chem 2010; 285: 16239-16247.

26. Graham KA, Kulawiec M, Owens KM, Li X, Desouki MM, Chandra D et al. NADPH oxidase 4 is an oncoprotein localized to mitochondria. Cancer Biol Ther 2010; 10: 223-231.

27. von Löhneysen K, Noack D, Wood MR, Friedman JS, Knaus UG. Structural insights into Nox4 and Nox2: motifs involved in function and cellular localization. Mol Cell Biol 2010; 30 961-975.

28. Wu RF, Xu YC, Ma Z, Nwariaku FE, Sarosi Jr GA, Terada LS. Subcellular targeting of oxidants during endothelial cell migration. J Cell Biol 2005; 171: 893-904.

29. Ushio-Fukai M. Compartmentalization of redox signaling through NADPH oxidase-derived ROS. Antioxid Redox Signal 2009; 11: 1289-1299.

30. Lipinski S, Till A, Sina C, Arlt A, Grasberger H, Schreiber S et al. Duox2-derived reactive oxygen species are effectors of NOD2-mediated antibacterial responses. J Cell Sci 2009; 122: $3522-3530$.

31. Wu RF, Ma Z, Liu Z, Terada LS. Nox4-derived $\mathrm{H}_{2} \mathrm{O}_{2}$ mediates endoplasmic reticulum signaling through local Ras activation. Mol Cell Biol 2010; 30: 3553-3568.

32. Chamulitrat W, Schmidt R, Tomakidi P, Stremmel W, Chunglok W, Kawahara $T$ et al. Association of gp91phox homolog Nox1 with anchorage independent growth and MAP kinase-activation of transformed human keratinocytes. Oncogene 2003; 22: 6045-6053.

33. Toledano MB, Planson AG, Delaunay-Moisan A. Reining in $\mathrm{H}_{2} \mathrm{O}_{2}$ for safe signalling. Cell 2010; 140: 454-456

34. Nediani C, Raimondi L, Borchi E, Cerbai E. Nitric oxide/reactive oxygen species generation and nitroso/redox imbalance in heart failure: from molecular mechanisms to therapeutic implications. Antioxid Redox Signal 2011; 14: 289-331.

35. Calabrese V, Cornelius C, Rizzarelli E, Owen JB, Dinkova-Kostova AT, Butterfield DA. Nitric oxide in cell survival: a janus molecule. Antioxid Redox Signal 2009; 11: 2717-2739.
36. Brüne B. Nitric oxide: NO apoptosis or turning it ON? Cell Death Differ 2003; 10: 864-869.

37. Fomenko DE, Koc A, Agisheva N, Jacobsen M, Kaya A, Malinouski M et al. Thiol peroxidases mediate specific genome-wide regulation of gene expression in response to hydrogen peroxide. Proc Natl Acad Sci USA 2011; 108: 2729-2734.

38. Barford D. The role of cysteine residues as redox-sensitive regulatory switches. Curr Opin Struct Biol 2004; 14: 679-686.

39. Tanner JJ, Parsons ZD, Cummings AH, Zhou H, Gates KS. Redox regulation of protein tyrosine phosphatases: structural and chemical aspects. Antioxid Redox Signal 2011; 15: 77-97.

40. Fomenko DE, Koc A, Agisheva $\mathrm{N}$, Jacobsen M, Kaya A, Malinouski $\mathrm{M}$ et al. Thio peroxidases mediate specific genome-wide regulation of gene expression in response to hydrogen peroxide. Proc Natl Acad Sci USA 2011; 108: 2729-2734.

41. Schröder K, Kohnen A, Aicher A, Liehn EA, Büchse T, Stein S et al. NADPH oxidase Nox2 is required for hypoxia-induced mobilization of endothelial progenitor cells. Circ Res 2009; 105: 537-544.

42. Rudolph J. Redox regulation of the Cdc25 phosphatases. Antioxid Redox Signal 2005; 7: 761-767.

43. Coant N, Ben Mkaddem S, Pedruzzi E, Guichard C, Tréton X, Ducroc R et al. NADPH oxidase 1 modulates WNT and NOTCH1 signaling to control the fate of proliferative progenitor cells in the colon. Mol Cell Biol 2010; 30: 2636-2650.

44. Naughton R, Quiney C, Turner SD, Cotter TG. Bcr-Abl-mediated redox regulation of the PI3K/AKT pathway. Leukemia 2009; 23: 1432-1440.

45. Giannoni E, Buricchi F, Grimaldi G, Parri M, Cialdai F, Taddei ML et al. Redox regulation of anoikis: reactive oxygen species as essential mediators of cell survival. Cell Death Differ 2008; 15: 867-878.

46. Giannoni $E$, Buricchi $F$, Raugei G, Ramponi $G$, Chiarugi P. Intracellular reactive oxygen species activate Src tyrosine kinase during cell adhesion and anchorage-dependent cell growth. Mol Cell Biol 2005; 25: 6391-6403.

47. Lee HY, Lee T, Lee N, Yang EG, Lee C, Lee J et al. Src activates HIF-1\{alpha\} not through direct phosphorylation of HIF-1\{alpha\}-specific prolyl-4 hydroxylase 2 but through activation of the NADPH oxidase/Rac pathway. Carcinogenesis 2011; 32: 703-712.

48. Rhee SG. H2O2, a necessary evil for cell signaling. Science 2006; 312: 1882-1883.

49. Lambeth JD, Kawahara T, Diebold B. Regulation of Nox and Duox enzymatic activity and expression. Free Radic Biol Med 2007; 43: 319-331.

50. Lee MY, San Martin A, Mehta PK, Dikalova AE, Garrido AM, Datla SR et al. Mechanisms of vascular smooth muscle NADPH oxidase 1 (Nox1) contribution to injury-induced neointimal formation. Arterioscler Thromb Vasc Biol 2009; 29: 480-487.

51. Brown DI, Griendling KK. Nox proteins in signal transduction. Free Radic Biol Med 2009; 47: 1239-1253.

52. Harper RW, Xu C, Eiserich JP, Chen Y, Kao CY, Thai P et al. Differential regulation of dual NADPH oxidases/peroxidases, Duox1 and Duox2, by Th1 and Th2 cytokines in respiratory tract epithelium. FEBS Lett 2005; 579: 4911-4917.

53. Rigutto S, Hoste C, Grasberger H, Milenkovic M, Communi D, Dumont JE et al. Activation of dual oxidases Duox1 and Duox2: differential regulation mediated by camp-dependent protein kinase and protein kinase C-dependent phosphorylation. J Biol Chem 2009; 284: 6725-6734.

54. Groemping Y, Lapouge K, Smerdon SJ, Rittinger K. Molecular basis of phosphorylationinduced activation of the NADPH oxidase. Cell 2003; 113: 343-355.

55. Lyle AN, Deshpande NN, Taniyama Y, Seidel-Rogol B, Pounkova L, Du P et al. Poldip2, a novel regulator of Nox4 and cytoskeletal integrity in vascular smooth muscle cells. Circ Res 2009; 105: 249-259.

56. Ellmark SH, Dusting GJ, Fui MN, Guzzo-Pernell N, Drummond GR. The contribution of Nox4 to NADPH oxidase activity in mouse vascular smooth muscle. Cardiovasc Res 2005; 65: 495-504.

57. Banfi B, Tirone F, Durussel I, Knisz J, Moskwa P, Molnar GZ et al. Mechanism of Ca2+ activation of the NADPH oxidase 5 (NOX5). J Biol Chem 2004; 279: 18583-18591.

58. Jagnandan D, Church JE, Banfi B, Stuehr DJ, Marrero MB, Fulton DJ. Novel mechanism of activation of NADPH oxidase 5. Calcium sensitization via phosphorylation. J Biol Chem 2007; 282: 6494-6507.

59. Kawahara T, Lambeth JD. Phosphatidylinositol (4,5)-bisphosphate modulates Nox5 localization via an N-terminal polybasic region. Mol Biol Cell 2008; 19: 4020-4031.

60. Fischer H. Mechanism and function of DUOX in epithelia of the lung. Antioxid Redox Signal 2009; 11: 2453-2465.

61. Lambeth JD. Nox enzymes, ROS, and chronic disease: an example of antagonistic pleiotropy. Free Radic Biol Med 2007; 43: 332-347.

62. Fukuyama M, Rokutan K, Sano T, Miyake H, Shimada M, Tashiro S. Overexpression of a novel superoxide-producing enzyme, NADPH oxidase 1, in adenoma and well differentiated adenocarcinoma of the human colon. Cancer Lett 2005; 221: 97-104.

63. Ginnan R, Guikema BJ, Halligan KE, Singer HA, Jourd'heuil D. Regulation of smooth muscle by inducible nitric oxide synthase and NADPH oxidase in vascular proliferative diseases. Free Radic Biol Med 2008; 44: 1232-1245.

64. Ushio-Fukai M, Nakamura Y. Reactive oxygen species and angiogenesis: NADPH oxidase as target for cancer therapy. Cancer Lett 2008; 266: 37-52.

65. Wu WS. The signaling mechanism of ROS in tumor progression. Cancer Metastasis Rev 2006; 25: 695-705

66. Jung J, Kim HY, Kim M, Sohn K, Kim M, Lee K. Translationally controlled tumor protein induces human breast epithelial cell transformation through the activation of Src. Oncogene 2011; 30: 2264-2274. 
67. Laurent E, McCoy III JW, Macina RA, Liu W, Cheng G, Robine S. Nox1 is overexpressed in human colon cancers and correlates with activating mutations in K-Ras. Int J Cancer 2008; 123: $100-107$.

68. Sallmyr A, Fan J, Datta K, Kim KT, Grosu D, Shapiro P. Internal tandem duplication of FLT3 (FLT3/ITD) induces increased ROS production, DNA damage, and misrepair: implications for poor prognosis in AML. Blood 2008; 111: 3173-3182.

69. Popp HD, Bohlander SK. Genetic instability in inherited and sporadic leukemias. Gen Chrom Can 2010; 49: 1071-1081.

70. Gruhne B, Sompallae R, Marescotti D, Kamranvar SA, Gastaldello S, Masucci MG. The Epstein-Barr virus nuclear antigen-1 promotes genomic instability via induction of reactive oxygen species. Proc Natl Acad Sci USA 2009; 106: 2313-2318.

71. Slupianek A, Poplawski T, Jozwiakowski SK, Cramer K, Pytel D, Stoczynska E et al. BCR/ ABL stimulates WRN to promote survival and genomic instability. Cancer Res 2011; 71: 842-851.

72. Young TW, Mei FC, Yang G, Thompson-Lanza JA, Liu J, Cheng X. Activation of antioxidant pathways in ras-mediated oncogenic transformation of human surface ovarian epithelial cells revealed by functional proteomics and mass spectrometry. Cancer Res 2004; 64: 4577-4584.

73. Benassi B, Fanciulli M, Fiorentino F, Porrello A, Chiorino G, Loda M et al. c-Myc phosphorylation is required for cellular response to oxidative stress. Mol Cell 2006; 21: 509-519.

74. Yeung BH, Wong KY, Lin MC, Wong CK, Mashima T, Tsuruo T et al. Chemosensitisation by manganese superoxide dismutase inhibition is caspase-9 dependent and involves extracellular signal-regulated kinase 1/2. Br J Cancer 2008; 99: 283-293.
75. Mochizuki T, Furuta S, Mitsushita J, Shang WH, Ito M, Yokoo Y et al. Inhibition of NADPH oxidase 4 activates apoptosis via the AKT/apoptosis signal-regulating kinase 1 pathway in pancreatic cancer PANC-1 cells. Oncogene 2006; 25: 3699-3707.

76. Brar SS, Kennedy TP, Sturrock AB, Huecksteadt TP, Quinn MT, Whorton AR et al. An $\mathrm{NAD}(\mathrm{P}) \mathrm{H}$ oxidase regulates growth and transcription in melanoma cells. Am J Physiol Cell Physiol 2002; 282: 1212-1224.

77. Kim EY, Seo JM, Cho KJ, Kim JH. Ras-induced invasion and metastasis are regulated by a leukotriene B4 receptor BLT2-linked pathway. Oncogene 2010; 29: 1167-1178.

78. Giannoni E, Buricchi F, Grimaldi G, Parri M, Cialdai F, Taddei ML et al. Redox regulation of anoikis: reactive oxygen species as essential mediators of cell survival. Cell Death Differ 2008; 15: 867-878.

79. Peshavariya H, Dusting GJ, Jiang F, Halmos LR, Sobey CG, Drummond GR et al. NADPH oxidase isoform selective regulation of endothelial cell proliferation and survival. Naunyn Schmiedebergs Arch Pharmacol 2009; 380: 193-204.

80. Terada LS, Nwariaku FE. Escaping anoikis through ROS: ANGPTL4 controls integrin signaling through Nox1. Cancer Cell 2011; 19: 297-299.

Cell Death and Disease is an open-access journal published by Nature Publishing Group. This work is licensed under the Creative Commons Attribution-Noncommercial-No Derivative Works 3.0 Unported License. To view a copy of this license, visit http://creativecommons.org/licenses/by-nc-nd/3.0/ 